
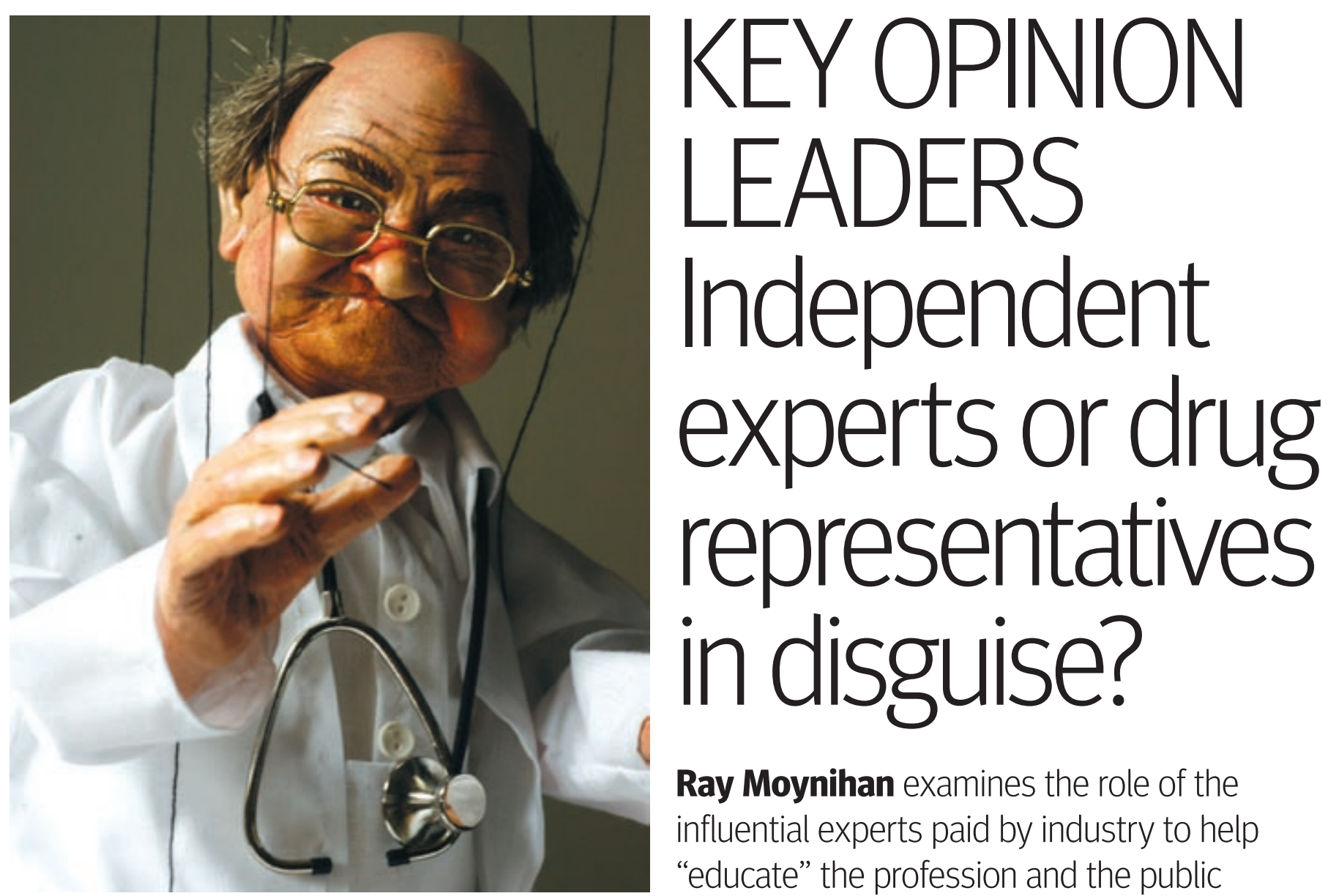

Ray Moynihan examines the role of the influential experts paid by industry to help "educate" the profession and the public

( $\mathrm{n}$ the world of medicine, "key opinion leader" is the somewhat Orwellian term used to describe the senior doctors who help drug companies sell drugs. ${ }^{1}$ These influential doctors are engaged by industry to advise on marketing and help boost sales of new medicines. Across all specialties, in hospitals and universities everywhere, many leading specialists are being paid generous fees to peddle influence on behalf of the world's biggest drug companies.

Kimberly Elliott, who was a drug company sales representative for almost two decades in the United States, puts it directly. "Key opinion leaders were salespeople for us, and we would routinely measure the return on our investment, by tracking prescriptions before and after their presentations," she said. "If that speaker didn't make the impact the company was looking for, then you wouldn't invite them back."

From the age of 23, Ms Elliott worked for several global drug companies, including Westwood Squibb, SmithKline Beecham, and Novartis, leaving the industry 18 years later, only last year. Many times a top national salesperson, part of her job was developing relationships with local and national opinion leaders, also described as "thought leaders." Ms Elliott says she would pay these respected doctors $\$ 2500$ ( $£ 1280$; $€ 1610)$ for a single lecture, which was largely based on slides supplied by the company. Sometimes the company would pay the fee to an academic centre, which would then pay the doctor. "These people are paid a lot of money to say what they say," she said. "I'm not saying the key opinion leaders are bad, but they are salespeople just like the sales representatives are."

In a candid interview with the $B M J$, the medical director at the Association of the British Pharmaceutical Industry, Richard Tiner, agreed key opinion leaders play an important role for drug companies. "Companies will employ consultants to help advise on marketing strategies ... and present and speak at conferences," he said.

\section{Generous earnings}

Two recent business intelligence reports on how drug companies identify, recruit, train, and pay their opinion leaders state that influential doctors can earn up to $\$ 400$ an hour. ${ }^{23}$ The reports were produced by a company called Cutting Edge, which works closely with drug company executives, and are available to purchase at around $\$ 8000$. A publicly available summary of one report shows that some doctors can earn more than $\$ 25000$ a year in advisory fees. A press release promoting the other report suggests that the average fee paid to a doctor for a "scientific speech" is more than $\$ 3000{ }^{4}$ Typically these speeches are delivered at educational events sponsored by companies.

The BMA said that although it might have

\section{Key opinion leaders-what fees can they command?}

Single lecture or scientific speech $\$ 3000$ (source: Marketwire)

Hourly rate for influential physicians offering advice-up to $\$ 400$ (source: Cutting Edge Information)

Work for drug companies on clinical trials-More than $\mathrm{f} 200$ an hour (source: BMA) 
had agreed fees for its members to be paid as key opinion leaders in the past, it had not happened recently. The association's fee guidance schedule, however, suggests members may charge drug companies more than $£ 200$ an hour for participation in clinical trials. Although many doctors retain these earnings, it's important to note that some donate their payments from drug companies to charities, or research.

\section{Global phenomenon}

Like drug marketing strategies, the use of key opinion leaders is a global phenomenon. In an article for UK based Pharmaceutical Marketing magazine describing the "tricks of the trade," drug company marketing staff are urged to work routinely with key opinion leaders and try to make them into "product champions." Importantly, marketing staff should find doctors who will endorse their products, "who may be further down the influence ladder," and then help "raise their profile, and so develop them into opinion leaders."

This industry guide says the first steps in recruiting and developing a set of opinion leaders are to "evaluate their views and influence potential;" build relationships with them; and then provide the doctors with "appropriate communications platforms" so they can "communicate on your behalf" with other doctors and the wider public. Drug companies are then encouraged to evaluate the performance of their key opinion leaders continuously to avoid "wasting money on the wrong people."

Another important trick of the trade is to maintain central databases of opinion leaders. Some small firms even offer special web based software to keep track of opinion leaders and show their return on investment. ${ }^{6}$ One firm offering such software, called $\mathrm{KOL}$, specialises in managing opinion leaders for drug companies. Its website states that although these "thought leaders" in the profession "may not write many prescriptions," they can "influence thousands of prescribers and hence prescriptions through their research, lectures, publications and their participation on advisory boards, committees, editorial boards, professional societies and guideline/consensus document development." The industry's Richard Tiner, accepts that drug companies often recruit senior specialists and evaluate the return on investment they may bring. They become an integral part of the company's marketing, education, and research strategies. "When these people are receiving a fee, they are in one sense in the employment of the company," he says, adding that this would mean their statements can be scrutinised under the industry's code of conduct. Asked how senior doctors with long term financial arrangements with drug companies could maintain independence, he said key opinion leaders are "free to speak about other medicines" and their presentations at influential medical meetings are "often quite balanced."

\section{Transparency}

Rejecting the view that doctors paid by industry may paint overly positive portraits of their sponsors' products, but conceding that hyping is not appropriate, Mr Tiner says the best antidote to these concerns is more transparency. All company payments to speakers should be routinely disclosed at medical meetings, he says. Responding to questions about whether such payments can be viewed as bribes to induce others to prescribe he said: "I don't think they are bribes. It's payment for work done, rather than a bribe." He agreed, however, that the work "might help to promote a particular medicine."

The former sales representative Ms Elliott says drug companies desperately need key opinion leaders. "There are a lot of physicians who don't believe what we as drug representatives say. If we have a KOL [key opinion leader] stand in front of them and say the same thing, they believe it." In January last year, after a car crash, and a worker's compensation claim, Elliott was fired from the company she was then working for. Disillusioned with what she saw as the industry's increasingly aggressive marketing strategies, she decided to leave the industry for good. Today she urges doctors who attend key opinion leader presentations to "take them with a grain of salt and go back and do your own research."

\section{Whose interest?}

David Blumenthal, a Harvard University researcher who has studied the relationships between industry and the profession, says company payments to key opinion leaders, rather than being corrupt, are simply not in the public interest. "I think these are legal relationships between consenting adults who have overlapping interests that are not consistent with the interests of the larger society or necessarily with the patients served by these physicians." Blumenthal is part of a small but growing global chorus, which includes advocacy groups No Free Lunch and Healthy Skepticism, that is calling for a major winding back of industry influence over the medical profession and in particular its education.

If industry's sponsorship of medical education is wound back, it is possible that more independent sources of funding will be secured. ${ }^{8}$ Yet if the speakers giving the educational presentations in any newly independent forums continue to be the overpaid "thought leaders" on the drug company payrolls, little, if anything, will have been gained.

Ray Moynihan is a visiting editor, $B M$

University of Newcastle, Newcastle,

New South Wales, Australia

Ray.moynihan@newcastle.edu.au

Competing interests: None declared.

1 Pharma Marketing Glossary www.pharma-mkting.com/ glossary/keyopinionleader.htm

2 Cutting Edge Information. Thought-leader compensation: establishing fair-market value. http:// cuttingedgeinfo.com/thoughtleadercompensation/ PH106_summary.pdf, summary.

3 Cutting Edge Information. Pharmaceutical opinion leader management. November 2007. www. cuttingedgeinfo.com/pharmaopinionleaders/index. htm\#body, summary.

4 Marketwire. Large pharmaceutical companies tend to pay triple what other size companies do for KOL speakers. Press release, 19 March, 2008.www. marketwire.com/mw/release. .do?id=834122.

5 CookJ. Practical guide to medical education. Pharmaceutical Marketing 2001;6:14-22.

6 KOL. The opinion leader management service. http:// kolonline.com/products-olms.asp.

7 KOL. Opinion leader development. http://kolonline. com/services-development.asp.

8 Spurgeon D. Continuing education should no longer be funded by drug industry, says CMAJ. $B M$ J 2008;336:742-3.

See HEAD TO HEAD p 1404

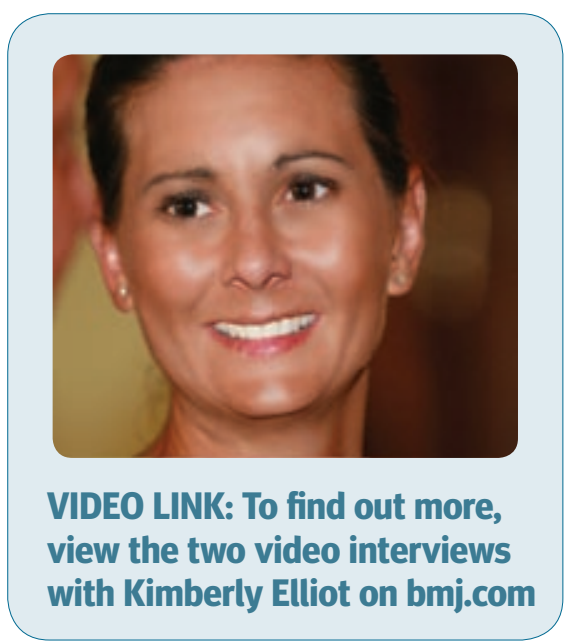

